\title{
FECHA DE EMISIÓN DE EFECTOS DE COMERCIO Y AUTORIZACIÓN NOTARIAL DE FIRMA
}

\author{
Alberto Viada Lozano \\ Profesor de Derecho Comercial \\ Universidad Católica del Norte (Sede Coquimbo)
}

En la ley 18.092, norma básica que regula las letras de cambio y pagarés y, por ende, los títulos de cré dito denominados "efectos de comercio", incluidos los cheques dados en pago de obligaciones, por expresa remisión del inciso tercero del artículo 11 del Decreto con Fuerza de Ley 707 de 1982, si bien contiene como mención obligatoria la fecha de emisión de los títulos, no establece alguna solución para el evento de que se omita dicha fecha, o ella no estuviere clara, o existieren dos fechas confundibles.

En efecto, al establecer en su artículo $1^{\circ}$, las enunciaciones que deberá contener una letra de cambio, en su $N^{\circ} 2$ dispone: "2. El lugar y fecha de su emisión. No obstante, si la letra no indicare el lugar de la emisión, se considerará girada en el domicilio del librador". Esta norma que suple la omisión del lugar de emisión es aplicable al pagaré, conforme a lo dispuesto en el artículo 107 de la misma ley, que ordena que, "en lo que no sean contrarias a su naturaleza y a las disposiciones del presente título, son aplicables al pagaré las normas relativas a la letra de cambio". puesto que a este respecto el artículo 102 de dicha ley sólo dispone: "El pagaré debe contener las siguientes enunciaciones:...5. El lugar y fecha de expedición". En cambio no es aplicable al cheque, ya que el inciso décimo del artículo 13 del Decreto con Fuerza de Ley 707, ya citado, aclara que: "si el cheque no indica lugar de giro, se le presume extendido en la plaza en que funciona la oficina sobre la cual fue girado". Tenemos resuelta legalmente, entonces, la omisión del lugar de expedición, pero nada suple la ley respecto de la omisión de la fecha de giro.

Por consiguiente, si cualquiera de los efectos de comercio nombrados carece de fecha de emisión, sólo cabe aplicar las sanciones contempladas en los artículos $2^{\circ}$ y 103 de la ley 18.092, por lo que los documentos no valdrán como letra de cambio, pagaré o cheque.

Sin embargo, el artículo 11 de la referida ley 18.092, aplicable a las letras de cambio, pagarés y cheques, señala que, "sin perjuicio de lo dispuesto en el artículo $2^{\circ}$, si la letra de cambio no contiene las menciones de que trata el artículo $1^{\circ}$, cualquier tenedor legítimo podrá incorporarlas antes del cobro del documento, sujetándose en todo ello a las instrucciones que haya recibido de los obligados al pago de la letra". Ergo, podría incorporarse al documento, antes de presentarlo a su cobro, la fecha de 
expedición, emisión o giro (la ley usa indistintamente estos vocablos para el mismo acto jurídico de dar vida a estos efectos de comercio). Obviamente, como lo exige la ley, esa fecha de expedición incorporada ulteriormente no puede ser distinta de la real, puesto que para ello el tenedor legítimo del documento debe sujetarse en todo a las instrucciones que haya recibido de los obligados al pago.

Además, la ley cifra importantes efectos jurídicos en la fecha de la emisión del efecto de comercio. Me permito transcribir, a vía de ejemplo, algunas disposiciones del Decreto Ley 3.475 de 1980, a saber: "Grávase con el impuesto que se indica...3) Letras de cambio, libranzas, pagarés, créditos simples o documentarios, otras órdenes de pago distintas de los cheques y cualquier otro documento que contenga una operación de crédito de dinero, $0,1 \%$ sobre su monto por cada mes o fracción que medie entre la emisión del documento y la fecha de vencimiento del mismo...", y en un inciso posterior aclara: "La renovación del plazo de vencimiento de los documentos citados, pagará el impuesto indicado en el inciso primero si por efecto de ella el plazo de vencimiento se extiende a más de un mes contado desde la emisión del documento..." (Art. $1^{\circ}$ ); o esta otra disposición: "Los impuestos del presente decreto ley se devengan al momento de emitirse los documentos gravados.-.." (Art. 14); o esta otra: "Salvo norma expresa en contrario los impuestos de la presente ley deberán pagarse dentro de los siguientes plazos: $N^{\circ} 1$. Instrumentos privados y otros documentos, dentro de los cinco primeros días hábiles a contar de su emisión...", o "N².- Los contribuyentes obligados a declarar renta efectiva mediante un balance general determinado de acuerdo a contabilidad completa, para los efectos de la Ley de la Rentas, dentro del mes siguiente a aquel en que se emiten los documentos" (Art. 15²), etcétera.

También la ley 18.092 contiene disposiciones que denotan la importancia de la fecha de emisión, por ejemplo: "La letra de cambio puede ser girada...A un plazo de la fecha de giro" (Art. 48); o "El pagaré puede ser extendido...2 A un plazo contado desde su fecha" (Art. 105); o "La letra girada a un plazo contado desde la vista, y que no sea aceptada en el plazo de un año a partir de la fecha de giro quedará sin valor..." (Art. 35 inc. $2^{\circ}$ ); o "La letra a la vista es pagadera a su presentación, y si no fuere pagada dentro del plazo de un año contado desde la fecha de su giro quedará sin valor..." (Art. 49); o "El término de una letra girada a un plazo de la fecha de giro, corre desde el día de su emisión" (Art. 50 inc. $2^{\circ}$ ), etcétera.

Igual importancia cabe encontrar en la reglamentación del cheque, Decreto con Fuerza de Ley 707 de 1982, donde, a vía de ejemplo, podemos citar las siguientes disposiciones: "...El cheque presentado al cobro antes del día indicado como fecha de

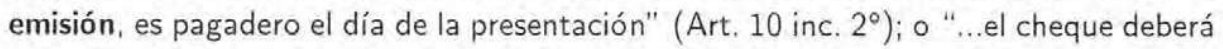
expresar, además:...El lugar y la fecha de la expedición". (Art. 13 inc. $3^{\circ}$ ); o "El portador de un cheque deberá presentarlo al cobro dentro del plazo de sesenta días, contados desde su fecha..." (Art. 23); o "La orden de no pagar el cheque puede ser 
dada por el librador solamente en los siguientes casos $\ldots 2^{\circ}$ Cuando el cheque hubiere sido alterado con respecto a la suma o a la persona del beneficiario, con posterioridad a la emisión". (Art. 26 inc. $2^{\circ}$ ); o "El portador de un cheque en moneda extranjera deberá presentarlo al cobro dentro del plazo de doce meses contados desde su fecha" (Art. 48), etcétera.

Resulta sorprendente, en consecuencia, que, dándole la ley tanta importancia a la fecha de giro, expedición o emisión de un efecto de comercio, y dependiendo de ella tantas consecuencias jurídicas, no se haya preocupado de establecer dicha fecha ante la circunstancia de que se omita en el documento, o la estampada en el documento sea incomprensible, imposible, no se ajuste a la realidad o, como veremos más adelante, exista duplicidad de fechas. Solamente existiría la sanción, ante la omisión de esta mención esencial, de que el documento en cuestión no valdrá como letra de cambio, pagaré o cheque.

La única norma supletoria relativa al tema la encontramos en la última frase del inciso final del artículo 40 del Decreto con Fuerza de Ley 707 de 1.982, que reglamenta al "cheque viajero" y dispone: "Para todos los efectos legales se tendrá por fecha de emisión del cheque aquella en que se hubiere llenado por el tomador". Pero esta norma es especialísima, dictada en consideración de la particular naturaleza del "cheque viajero", y, por ende, es de aplicación restringida al documento específico que reglamenta.

Ahora bien, entrando directamente al tema de esta disquisición, ¿qué ocurre con estos efectos de comercio, que no contienen formalmente una fecha de expedición, pero en los cuales aparece la firma del girador, librador o suscriptor autorizada por un notario, o por el oficial del Registro Civil en las comunas donde no tenga su asiento un notario?. Ello debido a que, conforme al $\mathrm{N}^{\circ} 4^{\circ}$ del artículo 434 del Código de Procedimiento Civil, "el juicio ejecutivo tiene lugar en las obligaciones de dar cuando para reclamar su cumplimiento se hace valer alguno de los siguientes títulos: $4^{\circ}$ Instrumento privado, reconocido judicialmente o mandado tener por reconocido...", agregando en su inciso segundo: "Tendrá mérito ejecutivo, sin necesidad de reconocimiento previo, la letra de cambio, pagaré o cheque, respecto del obligado cuya firma aparezca autorizada por un notario o por el oficial del Registro Civil en las comunas donde no tenga su asiento un notario".

Debe tenerse en cuenta que quienes emiten estos efectos de comercio son el librador o girador de la letra de cambio o del cheque y el suscriptor del pagaré, garantes y responsables solidarios del pago del documento, ya que el artículo 10 de la ley 18.092 dispone que "el librador garantiza la aceptación y el pago de la letra de cambio. Puede eximirse de la responsabilidad de la aceptación; pero toda cláusula por la cual se exima - limite su responsabilidad por el pago se tendrá por no escrita", y el artículo 79 de la 
misma ley aclara que "todos los que firman una letra de cambio, sea como libradores, aceptantes o endosantes, quedan solidariamente obligados a pagar al portador el valor de la letra, más los reajustes e intereses, en su caso". Y estas normas son aplicables al suscriptor de un pagaré, puesto que los artículos 106 y 107 de la misma ley resuelven que "el suscriptor de un pagaré queda obligado de igual manera que el aceptante de una letra de cambio", y "en lo que no sean contrarias a su naturaleza y las disposiciones del presente Título, son aplicables al pagaré las normas relativas a la letra de cambio". Por último, como ya se dijo, el inciso tercero del artículo 11 del Decreto con Fuerza de Ley 707 de 1982, dispone que "el cheque dado en pago se sujetará a las reglas generales de la letra de cambio, salvo lo dispuesto en la presente ley".

Resulta, entonces, que es de ordinaria ocurrencia, aunque con menos frecuencia en los cheques, que la firma del librador o girador de una letra de cambio o de un cheque, o la del suscriptor de un pagaré, esté autorizada por un notario, de modo que constituya un título ejecutivo en su contra. De este modo, aunque el documento no contuviere formalmente la fecha de expedición en el espacio impreso especialmente para ello, en realidad si la contiene, porque la autorización del notario debe expresar la fecha en que se firma. Así lo dispone el inciso primero del artículo 425 del Código Orgánico de Tribunales, que dice: "Los notarios podrán autorizar las firmas que se estampen en documentos privados, siempre que den fe del conocimiento o de la identidad de los firmantes y dejen constancia de la fecha en que se firman".

No existiría problema alguno, en el caso expuesto, para establecer la fecha de emisión del efecto de comercio, puesto que ella sería la que consta en la autorización notarial. Pero, ¿qué ocurrirá si existe discrepancia entre la fecha de la autorización de la firma del emisor del título de crédito y la fecha estampada en la parte impresa del formulario destinada a llenarse con la fecha de emisión?. Me permito exponer un ejemplo real de esta circunstancia:

Un campesino recurrió a una institución financiera y obtuvo un crédito de $\$ 500.000$,-, firmando un contrato privado de apertura de crédito datado el 27 de agosto de 1996, en el que, además de las cláusulas sobre intereses, comisiones y penas del infierno en caso de incumplimiento, cláusulas de aceleración, seguros y otras, se deja constancia que firmó un pagaré en blanco para facilitar el pago de todo lo adeudado y, textualmente, "viene en facultar irrevocablemente a "La Financiera", de acuerdo a lo dispuesto en el artículo 11 de la Ley 18.092 para que en su calidad de tenedora del pagaré $\mathrm{N}^{0}$..... ya firmado a la orden de dicha Institución, proceda a incorporar en dicho documento el monto adeudado con motivo de la línea de crédito, la fecha de vencimiento y cualquier otra estipulación para configurar un título ejecutivo".

El referido pagaré, $\mathrm{N}^{0} \ldots .$. , es un pagaré "a la vista", textualmente: "...debe y promete incondicionalmente pagar a la vista y a la orden de..." Y la autorización 
notarial es la siguiente: "Autorizo la firma de don...Céd. Nac. de Identidad $\mathrm{N}^{\circ}$..., con fecha de hoy como Deudor.- La Serena, veintinueve de Agosto de 1996".

El suscriptor cumplió a trompicones el servicio del préstamo, hasta que tuvo que recurrir a una renegociación para pagar un saldo, lo que se tradujo en un nuevo crédito, con el que pagó el saldo moroso, y firmó nuevos documentos, ninguno que sirviera de título ejecutivo, hasta que cesó definitivamente en el pago de sus obligaciones con la financiera. Ella, para cobrar ejecutivamente su crédito, recurrió al pagaré a la vista suscrito en blanco el 29 de agosto de 1996, y le agregó el monto de la deuda, \$791.414, y, en el espacio destinado al lugar y fecha de expedición le incorporó: "La Serena, 18 de Noviembre de 1998".

Tenemos, entonces, que un mismo pagaré tiene dos posibles fechas de emisión: Una, el 29 de agosto de 1.996, que, según hace fe el notario, fue la fecha en que se firmó el pagaré, y la otra, el 18 de noviembre de 1.998, fecha incorporada con posterioridad por la tenedora del documento. Es importante dilucidar cuál de ellas es efectivamente la fecha de emisión, por diversas razones:

En primer lugar, porque el tributo que afecta al documento, "de $0,5 \%$ de su monto" y que seguramente se calculó en base a los $\$ 500.000$.- del crédito por el cual se firmó, debió pagarse "dentro del mes siguiente a aquel en que se emiten los documentos", esto es, en el mes de septiembre de 1996, puesto que sabemos que estos efectos de comercio deben ser numerados correlativamente, registrados especialmente y timbrados por el Servicio de Impuestos Internos para su control tributario, por lo que, salvo que se hubiera invalidado, le corresponde pagar el impuesto en la oportunidad que, conforme a su registro y numeración correlativa, debió ser emitido. ¿Qué pasa, entonces, con el impuesto que debe pagarse por el pagaré por \$791.414.-, supuestamente emitido el 18 de noviembre de 1998?. Pues bien sabemos que el inciso primero del artículo $26^{\circ}$ de Decreto Ley 3.475 de 1980 dispone que "los documentos que no hubieren pagado los tributos a que se refiere el presente decreto ley, no podrán hacerse valer ante las autoridades judiciales, administrativas y municipales, ni tendrán mérito ejecutivo, mientras no se acredite el pago del impuesto con los reajustes, intereses y sanciones que correspondan ${ }^{\prime \prime}$.

Por otra parte, cabe aplicar lo dispuesto en el artículo 49 de la ley 18.092, que, siendo válido también para el pagaré de conformidad al artículo 107 de la misma ley, mutatis mutandi dice lo siguiente: "El pagaré a la vista es pagadero a su presentación, y si no fuere pagado dentro del plazo de un año contado desde la fecha de su giro quedará sin valor a menos de ser protestado oportunamente por falta de pago". Entonces, el pagaré en estudio perdió su valor pasada la medianoche del 29 de agosto de 1997, ¿ o debe considerarse como fecha de giro el 18 de noviembre de 1998 ? 
Otro aspecto que reviste suma importancia al analizar el tema tiene relación con la liquidación del crédito. ¿Qué o cuáles pagos parciales o totales deben rebajarse de la deuda? ¿ Deben imputarse al cumplimiento de la obligación cambiaria todos los pagos efectuados, voluntaria o forzadamente, desde el 29 de agosto de 1996, o sólo los que tengan fecha posterior al 18 de noviembre de 1998 ?

Creo que, aunque sólo sea por lo ya expuesto, resulta inconcusa la importancia de la cuestión que se analiza. Para mí, naciendo la obligación de los responsables del pago de los efectos de comercio con la firma del documento, como claramente lo expresa el artículo 79 de la ley 18.092, ya transcrito, la fecha de emisión del título de crédito es aquélla en que se firma por el girador o librador de la letra de cambio o cheque o por el suscriptor del pagaré. $Y$ si el documento fue firmado con anterioridad a la fecha que aparece como de su expedición, sobre todo si ello consta por la correspondiente autorización notarial, prevalece como fecha de emisión la fecha de suscripción. Ello está ratificado en la frase final del inciso segundo del artículo 10 del Decreto con Fuerza de Ley 707 de 1.982, que, repito, aclara: "El cheque presentado al cobro antes del día indicado como fecha de emisión, es pagadero el día de la presentación". (Obviamente, para que tal documento valga como cheque deberá contener la mención establecida en el inciso sexto del artículo 13 del mismo D.F.L.: "La firma del librador".). Y lo mismo debería considerarse si la autorización notarial señala como fecha de la firma del documento una posterior a la que aparecería como de su expedición.

Pero no sólo los argumentos precedentes me llevan a la conclusión de que la fecha de expedición de un efecto de comercio es la de su firma, establecida fehacientemente por la autorización de un Notario, sino que lo corrobora la aplicación de la norma de interpretación legal establecida en el inciso segundo del artículo 22 del Código Civil, la que permite que: "los pasajes obscuros de una ley pueden ser ilustrados por medio de otras leyes, particularmente si versan sobre el mismo asunto". Y para ello recurro al Decreto Ley 3.475 de 1980 , que, según vimos, establece tributos sobre cheques, pagarés y letras de cambio, en la mayoría de los cuales se considera la fecha de emisión del documento para determinar su monto, fecha desde que se devengan y oportunidad de pago. $Y$ entre sus disposiciones, al establecer las oportunidades en que deben ser pagados los impuestos que establece, el $\mathrm{N}^{\circ} \mathrm{I}$ del artículo $15^{\circ}$ aclara:

"Instrumentos privados y otros documentos, dentro de los cinco primeros días hábiles a contar de su emisión, esto es, de ser suscritos por sus otorgantes".

Por todo lo expuesto, reafirmo que, estando autorizada por un notario la firma del girador o librador de una letra de cambio o cheque, o del suscriptor del pagaré, la fecha de emisión del efecto de comercio es aquella en que consta que se firmó en la 
autorización notarial, no obstante cualquiera mención distinta al respecto que apareciere en el documento.

Así lo estimó la lltma. Corte de Apelaciones de La Serena, en el caso concreto que se expuso como ejemplo, al razonar, en el considerando sexto de su sentencia de fecha 15 de enero del 2002, que "se ha demandado ejecutivamente el pago del pagaré (a la vista) $N^{\circ} . .$. que fuera aceptado por ...con fecha 29 de Agosto de 1996, cuya firma como aceptante aparece autorizada en esa fecha, por el Notario..., fecha que debe tenerse como de la emisión del documento, sin perjuicio que unilateralmente la ejecutante haya consignado una fecha posterior de emisión del mismo".

CONCLUSION: En los efectos de comercio en que la firma del suscriptor, librador o girador apareciere autorizada por un Notario, (o por el oficial del Registro Civil en las comunas donde no tenga su asiento un Notario), la fecha de emisión, expedición o giro será aquélla que el ministro de fe señala en su autorización de la firma, no obstante que el documento contuviere alguna fecha distinta al respecto. 